\title{
Antimicrobial Activity of Urine after Ingestion of Differing Daily Doses of Cranberry Juice Cocktail in Pregnancy: A Pilot Study
}

\author{
Deborah A. Wing ${ }^{*}, 1$, Anita Shell ${ }^{1}$, Yee Lean Lee ${ }^{2}$, Sheryl Barron ${ }^{2}$, Szu-Yun Leu ${ }^{3}$ and \\ Thomas Cesario ${ }^{2}$
}

${ }^{l}$ Department of Obstetrics and Gynecology, Division of Maternal-Fetal Medicine, University of California, Irvine,
School of Medicine, USA
${ }^{2}$ Department of Medicine, Division of Infectious Disease, University of California, Irvine, School of Medicine, USA
${ }^{3}$ Department of Pediatrics, General Clinical Research Center, University of California, Irvine, School of Medicine, USA

\begin{abstract}
The objective of this study is to evaluate in vitro antimicrobial activity of urine from pregnant subjects following cranberry juice cocktail (CJC) or placebo ingestion against common pathogens causing asymptomatic bacteriuria. This study was conducted as an adjunct to a larger randomized, controlled trial. 4-hour uninfected urine samples were collected from 28 pregnant women who were randomized to cranberry or placebo in three groups: A. CJC $240 \mathrm{ml}$ two times daily (C, C; n=10), B: CJC in the AM, then placebo in the PM (C, P; n=10), C: placebo two times daily $(\mathrm{P}, \mathrm{P} ; \mathrm{n}=8)$. The $\mathrm{pH}$ of all specimens was adjusted to 7 and filtered. Aliquots were independently inoculated with overnight culture of $10^{2-3}$ cell/ml each of single strains of E. coli with both type I and type II fimbriae, K. pneumoniae, and C.albicans, and incubated. CFU/ml of each specimen was enumerated by subculture with quantitative plate counts in duplicate. There were no differences between groups for any of the pathogens studies based on treatment allocation. We demonstrated no differences in direct antimicrobial activity against E. coli, K. pneumonia or C. albicans in the urine of pregnant based on differing daily cranberry doses. This may be due to beta-error.
\end{abstract}

Keywords: Cranberry juice cocktail, asymptomatic bacteriuria, Escherichia coli.

\section{INTRODUCTION}

The use of cranberry (Vaccinium macrocarpon) fruits and leaves in folk medicine is longstanding. Diverse conditions including urinary tract infections, wound care and diabetes have been treated with cranberry products. There is growing interest in the use of cranberry for the prevention and treatment of urinary tract infections (UTI), and sales of cranberry make it one of the highest selling herbs in the United States [1].

The clinical effects of cranberry on urinary tract health are undergoing scientific scrutiny. The National Center for Complementary and Alternative Medicine has sponsored a number of ongoing clinical trials evaluating the protective effect of cranberry ingestion on urinary tract infections in women. Many of these trials are predicated on published controlled trials exploring the effectiveness of cranberry for the prevention of UTI $[2,3]$. Both reviews concluded that evidence from several well designed studies indicates that cranberry juice decreased the number of symptomatic UTIs in primarily female populations over time periods as long as 12 months [4-6]. Few studies looked at the use of cranberry for the treatment of UTI, however well designed studies are yet to be conducted [3,7]. No major adverse effects or interactions were reported or identified in these reviews or more recent studies $[8,9]$.

*Address correspondence to this author at the Department of ObstetricsGynecology, 101 The City Drive South, Building 56, Suite 800, Orange, CA 92868, USA; Tel: (714) 456-5967; E-mail: mfm@uci.edu
With mounting interest in the clinical use of cranberry, scientific curiosity about cranberry's antimicrobial mechanism of action grows. The exact antimicrobial action of cranberry remains under investigation. Initial proposed mechanism attributed the antimicrobial benefits to hippuric acid which has the potential to acidify the urine [10]. Later studies confirmed that cranberry juice can lower urinary $\mathrm{pH}$ $[11,12]$, however none of the urine samples were found to be bacteriostatic. More recently studies suggested that cranberry's activity is related to the inhibition of bacterial adherence to the uroepithelium. Recent evidence suggests that fructose, found in cranberries, interferes with adhesion of type 1 fimbriated (mannose-sensitive) E. coli to the uroepithelium [13], while other studies show that proanthocyanidins in cranberries inhibit the adherence of p-fimbriated (mannose-resistant) E. coli to the uroepithelium [14,15]. In fact recent studies suggest that cranberry juice irreversibly inhibits p-fimbriae preventing attachment of $E$. coli to the uroepithelium [16] as well as cultured vaginal epithelial cells [17].

In addition to the anti-adhesive effect, a possible antimicrobial activity has been suggested. In effect a laboratory study verified that concentrated cranberry juice had a direct antimicrobial activity in vitro [18]. However, despite the encouraging outcomes reported in the prevention studies and in laboratory studies looking at mechanism of action, evidence of direct antimicrobial activity in the urine after ingestion of cranberry has yet to be demonstrated. To evaluate the antimicrobial effect of urine specimens after 
ingestion of cranberry we conducted a pilot study assaying the direct antimicrobial activity of urine specimens taken from volunteer subjects after ingestion of a commercially available cranberry product, and found that $35 \%$ subjects had antimicrobial activity against $E$. coli, $65 \%$ against $K$. pneumoniae and $45 \%$ against C. albicans in specimens collected 2 to 6 hours after ingestion of cranberry following one day of exposure. There was a two-day evaluation of timed collections with one day of no exposure and another day of full exposure. No significant antimicrobial activity against $E$. coli or $C$. albicans was identified, however, for $K$. pneumoniae, $67 \%$ of the subjects had antimicrobial activity. The peak antibacterial activity appeared at 2-hours following cranberry ingestion [19].

We undertook this investigation as an adjunct to an ongoing clinical trial investigation employing methodologies previously tested in our laboratory.

\section{MATERIALS AND METHODOLOGY}

This study evaluated the in-vitro bioactivity (antimicrobial) of urine samples after ingestion of cranberry juice cocktail from pregnant women enrolled in an on-going randomized, controlled pilot investigation of the effect of CJC on the frequency of asymptomatic bacteriuria in pregnancy. The protocol was approved by the institutional review boards at the institutions in which the study was conducted at the University of California, Irvine and Long Beach Memorial Medical Center.

The methods for the clinical trial protocol are described elsewhere [20]. Briefly, women in the late first or early trimester trimester were randomized to three treatment arms: Group A: CJC $240 \mathrm{ml}$ doses twice daily at breakfast and dinner, Group B: CJC $240 \mathrm{ml}$ at breakfast and $240 \mathrm{ml}$ of a matching juice placebo at dinner, and Group C: Placebo 240 $\mathrm{ml}$ at breakfast and dinner. For this adjunct investigation, we randomly selected 28 pregnant subjects who were from each group, and also recruited 15 non-pregnant, reproductive aged women as controls. The pregnant subjects were ingesting juice daily, had been consuming juice for a minimum of three days prior to participation in this investigation, and we collected 4-hour urine samples from them including first morning voids after their usual dose of morning juice. No more than 6 hours elapsed between timing of last dose (morning dose) ingested and completion of urine collection. The non-pregnant controls were also randomly assigned to the same three treatment groups, and consumed the CJC or placebo products in the same regime for three days prior to urine collection.

The laboratory study team was blinded to the identity of and treatment provided to the subjects. All subjects were asked to abstain from taking any cranberry, during participation in the studies and during specimen collection.

\section{Cranberry Juice Product}

Cranberry juice cocktail (CJC) beverage containing 27\% cranberry juice was supplied by Fisher BioServices Corporation in collaboration with Ocean Spray Cranberries, Inc. (OS). It was formulated under contract with NCCAM to meet research needs and is not commercially available, although it is similar to retail CJC. A Drug Master File for this research-grade CJC is on file with the United States Food and Drug Administration.

Berries from Vaccinium macrocarpon Aiton grown and harvested under Good Agricultural Practices were used to manufacture under carefully controlled QC and QA programs and Good Manufacturing Practices batches of lowcalorie CJC from one lot of $100 \%$ cranberry juice concentrate. The CJC contained filtered water, cranberry juice concentrate, fructose, pectin, FDA-approved colorants (FD\&C Blue No. 1 and FD\&C Red No. 40), sodium citrate, ascorbic acid, sucralose, and acesulfame-K. Batches of CJC were standardized to the proanthocyanidin content.

The dosage form of the CJC consisted of $240 \mathrm{ml}$ in a hotfilled polypropylene bottle. The proanthocyanidin mean value of all CJC batches was $80 \mathrm{mg}$ as measured by Fisher BioServices using N,N-Dimethylacetamide (DMAC). Total phenolics by HPLC were $185 \mathrm{mg}$ and total anthocyanins by HPLC were $18.8 \mathrm{mg}$ per $240 \mathrm{ml}$. Stability monitoring of the concentrate and CJC was performed. Proanthocyanidin and other sensory, chemical and physical properties were stable at least 9 months in the CJC when stored at $2-8^{\circ} \mathrm{C}$. The CJC was stored under refrigerated conditions.

\section{Placebo Beverage}

The placebo beverage was formulated by OS to mimic the flavor (including sugar and acid profile) and color of the cranberry beverage. Ingredients included food- and/or pharmaceutical grade materials that mimic the composition of the cranberry beverage. There were no cranberry ingredients in the placebo beverage. It contained filtered water, fructose, glucose, pectin, citric acid, quinic acid, malic acid, artificial flavoring, and FDA-approved colorants (FD\&C Blue No. 1 and FD\&C Red No. 40). Fisher BioServices provided the placebo beverage in the identical polypropylene bottles used for the active beverage. Stability monitoring results indicate no degradation up to at least 9 months at 2$8^{\circ} \mathrm{C}$. Placebo beverage was stored under refrigerated conditions.

\section{Study Conduct}

The study was conducted concurrently with the parent clinical trial protocol. Twenty-eight pregnant women who were enrolled were randomly selected for recruitment into this adjunct investigation. They were asked to collect a fourhour urine sample including the first morning void on the day of a scheduled prenatal care and study visit. Standard urine processing as dictated by the study protocol was performed including urinalysis and urine culture.

Demographic data were collected for cases and controls, including age, gravidity, parity and race/ethnicity.

\section{Assessment}

In the laboratory, urines were filter-sterilized, aliquots of each of the specimens was then assayed for antimicrobial activity in vitro against a variety of common bacterial organisms which can be the cause of human Urinary Tract Infection (UTI).

The $\mathrm{pH}$ of all urine specimens was adjusted to the same $\mathrm{pH}$ as the baseline control specimens and filtered. Aliquots 
of each specimen were independently inoculated with $10^{2-}$ ${ }^{3}$ cell/ $\mathrm{ml}$ each of single strains of E. coli, K. pneumoniae, and $C$. albicans. A low inoculum of bacteria was used deliberately to mimic colonization and not an established infection. The organisms were the same strains utilized in our pilot study [18] and larger investigation [19]. After 24 hours of incubation for E. coli and K. pneumoniae, and 48 hours for $C$. albicans, colony forming units per milliliter (CFU/ $\mathrm{ml}$ ) of each specimen were enumerated by subculture with quantitative plate counts in duplicate.

\section{Data Analysis}

Antimicrobial activity was measured by $\mathrm{CFM} / \mathrm{ml}$ against E. coli, $K$. pneumoniae and C. albicans and data was presented with median and range (minimum, maximum). We applied Kruskal-Wallis test and Fisher's Exact test to evaluate differences between treatment groups. For variables with significant group difference, paired comparisons between the three treatment groups were followed with Wilcoxon test and Bonferroni's method was applied for multiple comparison adjustment. Significance level was set at 0.05 .

\section{Table 1. Demographic Characteristics}

\begin{tabular}{|c|c|c|c|}
\hline & $\mathbf{n}$ & median (range) & p-value \\
\hline$\underline{\text { Age }(y r)}$ & & & $0.26^{\mathrm{a}}$ \\
\hline Group A $(\mathrm{C}, \mathrm{C})$ & 10 & $29.0(19,38)$ & \\
\hline Group B $(\mathrm{C}, \mathrm{P})$ & 10 & $27.5(23,34)$ & \\
\hline Group $\mathrm{C}(\mathrm{P}, \mathrm{P})$ & 8 & $24.5(21,38)$ & \\
\hline Gravidity & & & $0 ., 0025^{\mathrm{a}, \mathrm{b}}$ \\
\hline Group A $(\mathrm{C}, \mathrm{C})$ & 10 & $3.5(2,8)$ & \\
\hline Group B $(\mathrm{C}, \mathrm{P})$ & 10 & $2.0(2,7)$ & \\
\hline Group C $(\mathrm{P}, \mathrm{P})$ & 8 & $1.0(1,4)$ & \\
\hline$\underline{\text { Parity }}$ & & & $0.0033^{\mathrm{a}, \mathrm{b}}$ \\
\hline Group A $(\mathrm{C}, \mathrm{C})$ & 10 & $1.0(1,5)$ & \\
\hline Group B $(\mathrm{C}, \mathrm{P})$ & 10 & $1.0(0,3)$ & \\
\hline Group C $(\mathrm{P}, \mathrm{P})$ & 8 & $0.0(0,1)$ & \\
\hline$\underline{\text { Race/Ethnicity }}$ & & & $0.97^{\mathrm{c}}$ \\
\hline $\begin{array}{l}\text { Group A }(\mathrm{C}, \mathrm{C}) \\
\text { Caucasian } \\
\text { Hispanic } \\
\text { African-American } \\
\text { Asian }\end{array}$ & 10 & $\begin{array}{c}2(20) \\
7(70) \\
1(10) \\
0(0)\end{array}$ & \\
\hline $\begin{array}{l}\text { Group B }(\mathrm{C}, \mathrm{P}) \\
\text { Caucasian } \\
\text { Hispanic } \\
\text { African-American } \\
\text { Asian }\end{array}$ & 10 & $\begin{array}{c}2(20) \\
7(70) \\
1(10) \\
0(0)\end{array}$ & \\
\hline $\begin{array}{l}\text { Group } \mathrm{C}(\mathrm{P}, \mathrm{P}) \\
\text { Caucasian } \\
\text { Hispanic } \\
\text { African-American } \\
\text { Asian }\end{array}$ & 8 & $\begin{array}{c}2(25) \\
5(62.5) \\
0(0) \\
1(12.5)\end{array}$ & \\
\hline \multicolumn{4}{|c|}{$\begin{array}{l}\text { Kruskal-Wallis test. } \\
\text { Paired comparison after Bonferroni's multiple comparison adjustment showe } \\
\text { only Group A and C are significantly different. } \\
\text { Fisher's exact test. } \\
\text { a presented as median (range) or number (\%). } \\
\text { ranberry; P, placebo. }\end{array}$} \\
\hline
\end{tabular}

\section{RESULTS}

There were statistically significant differences in the gravidity and parity between the multiple daily cranberry dosing group and the placebo-treated group; these are felt to be clinically insignificant. (Table $\mathbf{1}$ ). We found no differences in direct antimicrobial activity against E. coli, $K$. pneumonia, or C. albicans based treatment reflecting once, twice or no exposure to daily cranberry juice cocktail ingestion (Table 2).

Table 2. Antibacterial Activity of Urine Following Once or Twice Daily Cranberry Juice Cocktail or Placebo Ingestion

\begin{tabular}{|c|c|c|c|}
\hline & n & median (range) & p-value $^{\mathbf{a}}$ \\
\hline \hline E. coli $\left(\mathrm{x} 10^{5}\right)$ & & & $\underline{0.98}$ \\
\hline Group A $(\mathrm{C}, \mathrm{C})$ & 10 & $117.5(11.0,310.0)$ & \\
\hline Group B $(\mathrm{C}, \mathrm{P})$ & 10 & $105.0(41.0,385.0)$ & \\
\hline Group C (P, P) & 8 & $110.0(3.0,200.0)$ & \\
\hline K. pneumoniae $\left(\mathrm{x} 10^{5}\right)$ & & & 0.87 \\
\hline Group A $(\mathrm{C}, \mathrm{C})$ & 9 & $44.0(8.0,105.0)$ & \\
\hline Group B $(\mathrm{C}, \mathrm{P})$ & 10 & $45.5(0.6,180.0)$ & \\
\hline Group C $(\mathrm{P}, \mathrm{P})$ & 7 & $48.0(16.0,87.0)$ & \\
\hline C. albicans $\left(\mathrm{x} 10^{5}\right)$ & & & 0.67 \\
\hline Group A $(\mathrm{C}, \mathrm{C})$ & 10 & $5.9(0.8,17.5)$ & \\
\hline Group B $(\mathrm{C}, \mathrm{P})$ & 10 & $6.1(1.5,25.0)$ & \\
\hline Group C (P, P) & 8 & $7.0(4.1,20.5)$ & \\
\hline${ }^{\mathrm{a}}$ Kruskal-Wallis test. & & \\
\hline
\end{tabular}

Kruskal-Wallis test.

\section{DISCUSSION}

Cranberry is commonly recommended for treatment and prevention of urinary tract infections. Meta-analyses of clinical studies concluded that evidence supports a role for cranberry in the prevention of urinary tract infections but not in the treatment of an established infection [2,3,7]. Proposed mechanisms of action include anti-adherence [13-17,21,22], direct antibacterial effect $[18,19]$, changes in urine acidity $(\mathrm{pH}),[11,12]$, and activation of the nitric oxide pathway $[23,24]$. Laboratory studies identified a direct antibacterial activity of cranberry $[18,19]$, however little is known whether this activity is maintained after ingestion. In this study, we explored the presence of antimicrobial activity in the urine of pregnant and non-pregnant subjects after ingestion of a scientific grade cranberry juice product that was used for pilot clinical trial.

For this study we used an inoculation of $10^{2}-10^{3}$ instead of the more commonly accepted $10^{5}$. We reached this decision after careful review of the published data and the Cochrane reviews which conclude that cranberry was more effective in the prevention rather than treatment of urinary tract infection, and believe that this choice enhanced the sensitivity of our assay as described previously [19].

We are aware of the evidence which supports that the antibacterial effect is due to the anthocyanins and proantho- 
cyanidins fractions of cranberry. Our study methodology could have been improved with a series of timed urine collections such as collections at pre-treatment, 2, 4 and 6 hours after ingestion of the cranberry juice cocktail and placebo to determine time of maximal effect. A recent study by Ohnishi et al. demonstrated the urinary levels of anthocyanins reached a maximum between 3 and 6 hours after ingestion of cranberry [25]. Because of the physiological changes in pregnancy which include an increase in glomerular filtration rate, the time to maximal urinary anthocyanin concentration may differ.

Our study suggests that the antibacterial activity against E. coli after ingestion of cranberry juice cocktail following multiple daily dosing or single daily dosing was not significantly different between subjects. This confirms findings from 2 recent published studies exploring the antibacterial activity of urine after ingestion of cranberry [26,27]. Monroy-Torres and colleagues studied 20 healthy women between the ages of 19 and 24 years who provided urine samples before and 3 hours after drinking $250 \mathrm{cc}$ of cranberry juice. Urine samples were incubated for 1-2 hours only then plated. No significant reduction in the number of E. coli colonies were seen after cranberry ingestion [27] Tong and colleagues found in 10 young healthy Chinese adults who collected urine at 3 hour intervals on 2 consecutive days and on day 2 drank $750 \mathrm{ml}$ of cranberry juice, that there were no statistically significant differences in $E$. coli colony counts after a 24-hour incubation between the control (day 1) and urine specimens collected on day 2 after ingestion of the cranberry juice [26]. Although these studies used different forms (juice and tablets) and doses of cranberry, the final result was the same regardless of the time of urine collection after cranberry ingestion.

In this study we also explored the presence of antimicrobial activity against less common causes of UTI, such as $K$. pneumoniae. We found no significant differences in the number of $E$. coli, $C$. albicans or $K$. pneumoniae colonies after ingestion of the varying doses of cranberry juice cocktail or placebo. The former result differs from our previous investigation in which antimicrobial activity against $K$. pneumoniae was detected in the urine of 6 out of 9 subjects after ingestion of the cranberry capsules [19]. We have previously postulated that the antimicrobial activity of cranberry against $K$. pneumoniae is probably due to other factors than the anti-adherence activity reported for E. coli.

Further studies are warranted to better understand the nature of the factors responsible for the antimicrobial activity in urine following cranberry juice ingestion, as well as to better characterize the bacterial spectrum of these factors and how they might be enhanced. These could lead to determinations of optimal methods and timing of dosing.

\section{CONCLUSION}

We found no difference in antimicrobial activity against E. coli, K. pneumoniae or C. albicans based on therapy. The lack of difference based on treatment may reflect a beta-error resulting from small sample size, a relatively low concentration of cranberry in the juice products provided, or timing related to ingestion. Additional studies are needed to further explore the antimicrobial activity using different study methodology, and different formulations and doses of cranberry products.

\section{TRIAL REGISTRATION}

\author{
Current Controlled Trials NCT00506025.
}

\section{REFERENCES}

[1] Blumenthal M, Ferrier GKL. Total Sales of Herbal Supplements in United States Show Steady Growth. HerbalGram 2006; 71: 64-66.

[2] Jepson RG, Craig JC. A systematic review of the evidence for cranberries and blueberries in UTI prevention. Mol Nutr Food Res 2007; 51: 738-745.

[3] Jepson RG, Craig J. Cranberries for preventing urinary tract infections. Cochrane Database Syst Rev 1 2008: CD001321. Review.

[4] Avorn J, Monane M, Gurwitz JH, Glynn RJ, Choodnoviskiy I, Lipsitz LA. Reduction of bacteriuria and pyuria after ingestion of cranberry juice. JAMA 1994; 271: 751-4.

[5] Stothers L. A randomized trial to evaluate effectiveness and cost effectiveness of naturopathic cranberry products as prophylaxis against urinary tract infection in women. Can J Urol 2002; 9: 155862.

[6] McMurdo ME, Bissett LY, Price RJ, Phillips G, Crombie, IK. Does ingestion of cranberry juice reduce symptomatic urinary tract infections in older people in hospital? A double-blind, placebocontrolled trial. Age Ageing 2005; 34: 256-61.

[7] Jepson RG, Mihaljevic L, Craig J. Cranberries for treating urinary tract infections. Cochrane Database Syst Rev 2000; 2: CD001322.

[8] Lilja JJ, Backman JT, Neuvonen PJ. Effects of daily ingestion of cranberry juice on the pharmacokinetics of warfarin, timzanidine, and midazolam--probes of CYP2c9, VYP1A2, and CYP3A4. Clin Pharmacol Ther 2007; 6(81): 833-839.

[9] Li Z, Seeram NP, Carpenter CL, Thames G, Minutti C, Bowerman $\mathrm{S}$. Cranberry does not affect prothrombin time in male subjects on Warfarin. J Am Diet Assoc 2006; 12(106): 2057-2061.

[10] Foo LY, Porter LJ. The phytochemistry of proanthocyanidin polymers. Photochemistry 1980; 19: 1747-54.

[11] Jackson B, Hicks LE. Effect of cranberry juice on urinary $\mathrm{pH}$ in older adults. Home Health Nurse 1997; 15(3): 198-202.

[12] Kinney AB, Blount M. Effect of cranberry juice on urinary $\mathrm{pH}$ Nurs Res 1979; 28(5): 287-290.

[13] Zafriri D, Ofek I, Adar R, Pocino M, Sharon N. Inhibitory activity of cranberry juice on adherence of type 1 and type $\mathrm{P}$ fimbriated Escherichia coli to eucaryotic cells. Antimicrob Agents Chemother 1989; 33(1): 92-98.

[14] Foo LY, Lu Y, Howell AB, Vorsa N. A-Type proanthocyanidin trimers from cranberry that inhibit adherence of uropathogenic $\mathrm{P}$ fimbriated Escherichia coli. J Nat Prod 2000; 63(9): 1225-1228.

[15] Howell AB, Vorsa N, Der Marderosian A, Foo LY. Inhibition of the adherence of P-fimbriated Escherichia coli to uroepithelial-cell surfaces by proanthocyanidin extracts from cranberries. N Engl J Med 1998; 339(15): 1085-86.

[16] Ahuja S, Kaack B, Roberts J. Loss of fimbrial adhesion with the addition of Vaccinum macrocarpon to the growth medium of $\mathrm{P}$ fimbriated Escherichia coli. J Urol 1998; 159(2): 559-562.

[17] Gupta K, Chou MY, Howell A, Wobbe C, Grady, Stapleton AE. Cranberry products inhibit adherence of P-fimbriated Escherichia Coli to primary cultured bladder and vaginal epithelial cells. J Urol 2007; 177: 2357-60.

[18] Lee YL, Owens J, Thrupp L, Cesario TC. Does cranberry juice have antibacterial activity? JAMA 2000; 283(13): 1691

[19] Lee YL, Najm WI, Owns J, Thrupp L, Barron S, Shanbrom E, Cesario T. Antimicrobial Activity of Urine after Ingestion of Cranberry: A Pilot Study. Evid Based Complement Alternat Med 2008; eCAM Advance Access: 10.1093/ecam/nem183.

[20] Wing DA, Rumney PJ, Preslicka CW, Chung JH. Daily cranberry juice for the prevention of asymptomatic bacteriuria in pregnancy: A randomized, controlled pilot study. J Urol 2008; 180(4): 13671372

[21] Howell AB, Foxman B. Cranberry juice and adhesion of antibioticresistant uropathogens. JAMA 2002; 287(23): 3082-83. 
[22] Howell AB, Reed JD, Krueger CG, Winterbottom R, Cunningham DG, Leahy M. A-type cranberry proanthocyanidins and uropathogenic bacterial anti-adhesion activity. Phytochemistry 2005; 66(18): 2281-2291.

[23] Raz R, Chazan B, Dan M. Cranberry juice and urinary tract infection. Clin Infect Dis 2004; 38: 1413-9.

[24] Maher MA, Mataczynski H, Stefaniak HM, Wilson T. Cranberry juice induces nitric oxide-dependent vasodilation in vitro and its infusion transiently reduces blood pressure in anesthetized rats. $\mathbf{J}$ Med Food 2000; 3(3): 141-47.

[25] Ohnishi R, Ito H, Kasajima N, Kaneda M, Kariyama R, Kumon H et al. Urinary excretion of anthocyanins in humans after cranberry juice ingestion. Biosci Biotechnol Biochem 2006; 70(7): 1681-87.

[26] Tong HS, Chang S. Effect of ingesting cranberry juice on bacterial growth in urine. Am J Health Syst Pharm 2006; 63: 1417-19.

[27] Monroy-Torres R, Macias AE. Does cranberry juice have bacteriostatic activity? Rev Invest Clin 2005; 57(3): 442-46.

Received: March 17, 2010

(C) Wing et al.; Licensee Bentham Open.

This is an open access article licensed under the terms of the Creative Commons Attribution Non-Commercial License (http://creativecommons.org/licenses/bync/3.0/), which permits unrestricted, non-commercial use, distribution and reproduction in any medium, provided the work is properly cited. 